\section{Patterning in goldfish as a function of magnitude of reinforcement*}

\author{
R. C. GONZALEZ \\ Bryn Mawr College, Bryn Mawr, Pa 19010
}

Single alternation of reinforcement and nonreinforcement produced a tendency to respond less rapidly after reinforcement than after nonreinforcement in goldfish trained with large reward. The alternating schedule did not produce this tendency in fish trained with small reward, nor did a quasirandom $50 \%$ schedule produce it in fish trained with large reward. These results indicate that patterning in fish is a function of magnitude of reinforcement and a product of the discrimination of the aftereffects of reinforcement and nonreinforcement.

In a recent paper devoted in part to an examination of the extent to which the behavior of fish is subject to control by the aftereffects of the consequences of immediately preceding responses, Mackintosh (1971) reports a failure to obtain pattermed responding in goldfish trained in discrete trials with a single-alternation (SA) schedule of rei $n$ forcement (R) and nonreinforcement $(\mathrm{N})$. Attributing a previous failure to demonstrate patterning (more rapid responding following $\mathrm{N}$ than following $\mathrm{R}$ trials as a function of the $\mathrm{SA}$ schedule) in African mouthbreeders (Gonzalez, Eskin, \& Bitterman, 1961) to the use, under the conditions of that experiment, of too short an intertrial interval, kut satisfied, apparently, with the conditions of his own experiment, Mackintosh concludes that learning the SA pattern, an easy problem for rats, is virtually impossible for fish. The particular difficulty for fish, he suggests, is not that the aftereffects of $N$ and $R$ per se are indistinguishable, but that the memory of the aftereffects is so susceptible to interference-produced forgetting that "under normal conditions" fish are unable to remember which consequence of response, $N$ or $R$, occurred on the immediately preceding trial.

On the assumption that the forgetting of the consequences of response on a given trial is produced by proactive interference (PI) from the outcomes of earlier trials in the series, and based on the finding in humans that PI increases with the temporal contiguity of prior and test list learning (Underwood \& Freund, 1968), Mackintosh sought evidence of discrimination of aftereffects in a new

$\times$ This research was supported by NIMH Grant 15902. The assistance of Mrs. Gertrude Johnson is acknowledged with gratitude. group of goldfish given only two trials per day--RN and NR sequences alternated daily. Under these conditions, with the presumed source a tendency to respond more rapidly on the second trial of each day after an $\mathrm{N}$ than after an $R$ trial.

It is unnecessary, of course, to invoke memory as the process underlying discrimination of the alternating pattern of reinforcement, certainly in massed trials. All that is necessary for the development of patterned responding is that $\mathrm{N}$ and $\mathrm{R}$ occasion discriminably different stimuli ( $\mathrm{S}^{\mathrm{N}}$ and $\left.\mathrm{S}^{\mathrm{R}}\right)$, that traces of these stimuli be present at the start of the next trial, and that the animal be differentially reinforced for response in the presence of these traces. The problem thus reduces to a simple successive discrimination of interoceptive stimuli, and the difficulty of the problem should be expected to vary inversely with the discriminability of the traces of $\mathrm{SN}^{\mathrm{N}}$ and $S^{R}$. Mackintosh's two-trial procedure provides a means of increasing discriminability because stimulus traces dissipate in the 24-h intersession interval and are unavailable, therefore, to interact with and modify the single trace of each day's first trial. Discriminability can also be increased, of course, by varying the conditions of reinforcement which directly provide the stimuli to be discriminated. In rats, for example, degree of patterning in SA situations has been shown to vary markedly with (Gonzalez, Bainbridge, \& Bitterman, 1966). The purpose of the present experiment was to determine whether patterning in fish was affected in like manner by magnitude of reward.

\section{SUBJECTS}

The Ss were 27 experimentally naive goldfish, 4-5 in. long, obtained from a local dealer and housed in individual 2-gal tanks set on open shelves in a temperature-controlled laboratory. of PI 24 h removed, the fish developed magnitude of reinforcement

\section{APPARATUS}

Each $S$ was trained in its 2-gal living tank. The tank was carried to an enclosure of black Plexiglas equipped with a hinged side and a hinged lid which were closed when the tank was inserted. The enclosure was illuminated diffusely by a houselight. Fixed to one end of the lid on a thin metal rod was a target, 1.25 in. in diam, which could be illuminated with white light. Striking at or pressing against this target was reinforced with live Tubifex worms delivered by a feeder at the end of the tank opposite the target. All events of the experiment were programmed automatically; a printing counter, driven by a pulse stream generator, was used to measure response latencies in units of $0.1 \mathrm{sec}$.

\section{PROCEDURE}

After adaptation to the experimental situation, Ss were trained to strike at the target, baited at first and then unbaited. Each contact of $S$ with the target was reinforced with 1 worm for 9 randomly selected Ss and with 10 worms for the remaining 18 Ss. Then there were three daily sessions of 40 reinforced trials each with the unbaited target. On the basis of their performance during these 3 days, the 10-worm Ss were divided into two matched groups of 9 Ss each, an alternating (10) group and a Gellermann (10) group; the 1-worm Ss constituted a second alternating group (1) trained with the smaller magnitude of reinforcement.

The experiment proper consisted of 66 daily sessions of 40 trials each. For the two alternating groups, odd trials were reinforced and even trials were unreinforced. For the Gellermann group, the schedule of reinforcement followed selected Gellermann (1933) orders, with the restriction that the first trial of each day was reinforced and the last trial unreinforced. Each trial began with the offset of the houselight, the onset of the target light, and the activation of the printing counter. Response to the target turned off the target light, turned on the houselight, produced a print of latency, and, on reinforced trials, activated the feeder (which discharged either 1 or 10 worms). The intertrial interval was $45 \mathrm{sec}$.

\section{RESULTS}

In Fig. 1, the difference in mean log latency on trials following reinforcement and nonreinforcement is plotted for all groups in 3-day blocks. [Three Ss were lost in the course of the experiment, and the data presented are based on 9,8 , and $7 \mathrm{Ss}$ in the alternating (10), Gellermann (10), and alternating (1) groups, respectively.] Nonreinforcement had no systematic effect on the performance of either the 10-worm 




Fig. 1. Mean log latency on trials following reinforcement minus mean log latency on trials following nonreinforcement. (A positive value indicates faster response after nonreinforcement.)



Fig. 2. Mean log latency for the alternating (10) group on each trial of the last day of the experiment.

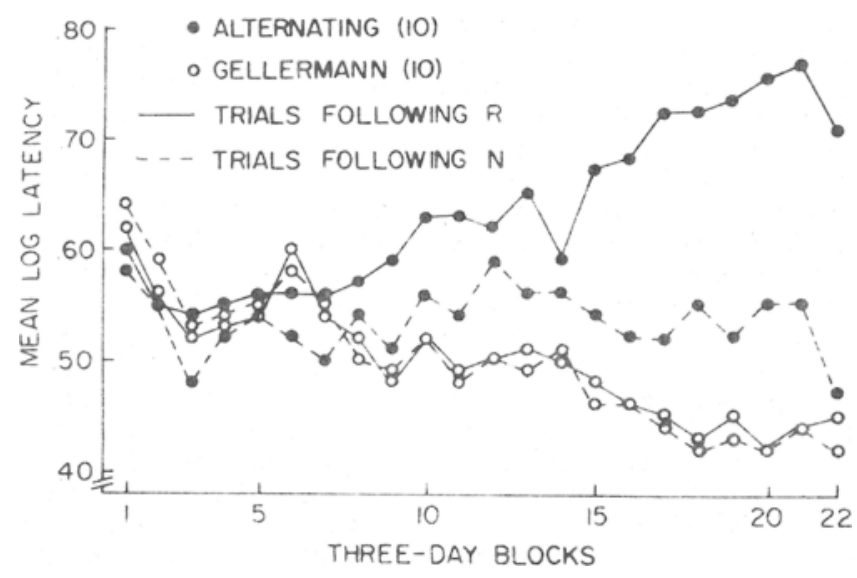

Fig. 3. Differential performance of the alternating (10) and the Gellermann (10) groups to the aftereffects of reinforcement and nonreinforcement.
Gellermann group or the 1-worm alternating group; the latencies of these Ss throughout training were essentially the same after $\mathrm{N}$ as after $\mathrm{R}$ trials. By contrast, the 10-worm alternating group progressively developed a tendency to pattern, which began as early as the third block of training but became pronounced only after the eighth block, after which there was virtually no overlap of its distribution of difference scores with those of the other two groups. A repeated-measures analysis of variance yielded significant effects of groups ( F $=29.8, \mathrm{df}=2 / 21, \mathrm{p}<.01)$, blocks $(\mathrm{F}$ $=10.2, \mathrm{df}=21 / 441, \mathrm{p}<.01)$, and of the interaction of Groups by Blocks ( $F$ $=12.2, \mathrm{df}=42 / 441, \mathrm{p}<.01)$. Subsequent orthogonal comparisons showed that the 10-worm alternating group differed significantly from the other two groups $(F=59.5, \mathrm{df}=1 / 21$, $\mathrm{p}<.01$ ), which did not differ from each other $(F<1)$.

An indication of the degree of control by the aftereffects of $\mathrm{N}$ and $\mathrm{R}$ which developed in the 10-worm alternating Ss may be gained from inspection of Fig. 2, in which their trial-by-trial performance on the final day of training is shown. Although not as sharp as that for rats trained under the most favorable conditions of an analogous experiment (Gonzalez et al, 1966), this trial-by-trial plot attests undeniably to the fish's ability to utilize aftereffects in the discrimination of the SA pattern of partial reinforcement. As is the case in rats (Gonzalez et al, 1966), the development of patterned responding in fish may be traced primarily to the progressive development of inhibitory properties by the aftereffects of reinforcement. In Fig. 3, performance on trials following reinforcement and trials following nonreinforcement is shown separately for the alternating (10) and the Gellermann (10) groups. As compared with the Gellermann group, the latency of response of the alternating group became moderately longer following $\mathrm{N}$ trials and markedly longer following $R$ trials. $A$ three-factor mixed design analysis of variance yielded $F$ ratios significant beyond the .01 level for all the main effects and interactions and for the difference between the two groups on trials following reinforcement, but not for the difference between groups on trials following nonreinforcement $(\mathrm{F}=$ $2.69, \mathrm{df}=1 / 15, \mathrm{p}>.05$ ).

\section{DISCUSSION}

In the SA problem, the only basis for discrimination is the difference between the internal stimuli occasioned by reinforcement and nonreinforcement. With the results for the Gellermann (10) group serving as control for sequence of $\mathrm{N}$ and $\mathrm{R}$ trials, 
the data for the alternating (10) group demonstrate that such stimuli can be discriminated by goldfish and come to serve cue functions. Taken together with the data for the alternating (1) group, the results of this experiment show that patterning in fish varies directly with magnitude of reinforcement, just as it does in rats.

It is interesting to note that it is precisely under the conditions which yielded patterning in the present experiment-massed trials, large reward-that the partial reinforcement effect (PRE) has been obtained in fish (Gonzalez \& Bitterman, 1967). The PRE has not appeared in massed trials with small reward nor in spaced trials, even with large reward (Gonzalez, Behrend, \& Bitterman, 1965). All the data on partial reinforcement in fish can, in fact, be dealt with nicely in terms of the carryover of stimulus traces (Hull, 1952; Sheffield, 1949). In spaced trials, there is no PRE in fish because $S^{N}$ and $S^{R}$ dissipate in the intertrial interval and cannot be present at the time the animal is reinforced for responding. In massed trials, large as compared with small reward increases the resistance to extinction of both partially reinforced (Gellermann) and consistently reinforced fish, but much more so that of the partially reinforced animals because, for them, the larger reward increases the strength of the tendency to respond both to $S^{N}$ and $S^{R}$. In the consistent animals, it directly strengthens only the tendency to respond to $S R$, but it is the strength of the tendency to respond in the presence of $\mathrm{S}^{\mathrm{N}}$ which is measured in extinction.

With respect to Mackintosh's hypothesis about patterning in fish, it should be noted that his "argument was only that aftereffects play a less important role in the control of behavior in fish than in rats, not that they play no role at all [Mackintosh, 1971 , p. 229]." He cites the massed trials partial reinforcement data and also data on repeated acquisitions and extinction in fish (Gonzalez et al, $1967)$ as "instances of behavior controlled by the aftereffects of preceding conditions of reinforcement
[ $\mathrm{M} \mathrm{a} \mathrm{c} \mathrm{k} \mathrm{i} \mathrm{n} \mathrm{t} \mathrm{o} \mathrm{s} \mathrm{h,} 1971$, p. 229]." Prepared, then, in advance of his experiment, to find some evidence of patterning in fish, Mackintosh took the results for his alternating animals to mean that some process was engendered in the course of training with a long series of trials-he assumed it was proactive interference-which operated to mask the discrimination of aftereffects. In the light of the results of the present experiment, the appeal to disruption of memory traces seems unnecessary; the failure of his SA animals to pattern seems more likely accountable for in terms of the use of a small magnitude of reward. (It is not possible, however, to specify the level of reward independently of the results of his experiment, because he used Tetramin tube food, a liquid reinforcer for which there are as yet no data on magnitude functions. It is possible, too, of course, that the liquid reinforcer and live worms differ appreciably in the richness of their stimulus properties.)

With respect to Mackintosh's hypothesis that the differences between fish and rats which have appeared in experiments on the effects of complete and incomplete reductions of reward magnitude (Gonzalez \& Bitterman, 1967; Lowes \& Bitterman, 1967; Mackintosh, 1971) may be accounted for simply on the assumption that fish, as compared with rats, discriminate more poorly between very recent and less recent aftereffects and are therefore less sensitive to changes in the conditions of reinforcement, it should be noted that the very nature of the proposition poses a difficult problem for experimental analysis. Certainly, the hypothesis cannot be tested by comparing fish and rats in absolute terms-e.g., number of trials to some performance criterion-because absolute levels of performance in each species vary appreciably with the experimental conditions under which each is studied, and it is not possible to equate the parameters of experiments with the two animals. This is not to say, of course, that the hypothesis necessarily is untenable, but only that tests of its validity await the development of a suitable technique.

In the meantime, with respect to the question of aftereffects and patterning, the results of the present experiment show that fish and rats are affected in the same way by manipulation of the same variable; there is no reason to assume, therefore, that the aftereffects of $\mathrm{N}$ and $R$ play any different role in the control of the instrumental behavior of the two animals.

\section{REFERENCES}

GELLERMANN. L. W. Chance orders of alternating stimuli in visual discrimination experiments. Journal of Genetic Psychology, 1933, 42, 206-208.

GONZALEZ, R. C., \& BITTERMAN, M. E. $P$ artial reinforcement effect in the goldfish as a function of amount of reward. Journal of Comparative \& Physiological Psychology, 1967, 64, 163-167.

GONZALEZ, R. C., BAINBRIDGE, P., \& BI T TERMAN, M. E. Discrete-trials lever-pressing in the rat as a function of pattern of reinforcement, effortfulness of response, and amount of reward. Journal of Comparative \& Physiological Psychology, 1966, 61, 110-122.

GONZALEZ, R. C., BEHREND, E. R., \& BIT TERMAN, M. E. Partial reinforcement effect in the fish: Experiments with spaced trials and partial delay. American Joumal of Psychology, $1965,78,198-207$.

GONZALEZ, R. C., ESKIN, R. M., \& BITTERMAN. M. E. Alternating and random partial reinforcement in the fish with some observations on asymptotic resistance to extinction. American Journal of Psychology, 1961, 74, $561-568$.

GONZALEZ, R. C., HOLMES, N. K., \& BITTERMAN, M. E. Resistance to extinction in the goldfish as a function of frequency and amount of reward. American Journal of Psychology, 1967, 80, 269-275.

HULL, C. L. A behavior system. New Haven: Yale University Press, 1952

LOWES, G., \& BITTERMAN, M. E. Reward and learning in the goldfish. Science, $1967,157,455-457$.

MACKINTOSH, N. J. Reward and aftereffects of reward in the learning of goldfish. Journal of Comparative \& Physiological Psychology, 1971、76, 225-232.

SHEFFIELD, V. F. Extinction as a function of partial reinforcement and distribution of practice. Journal of Experimental Psychology, 1949, 39, 511-526.

UNDERWOOD. B. J., \& FREUND, J. S. Effect of temporal separation of two tasks on proactive inhibition. Journal of Experimental Psychology, 1968, 78, 50-54. 